Article

\title{
Experiment-Based Sensitivity Analysis of Scaled Carbon-Fiber-Reinforced Elastomeric Isolators in Bonded Applications
}

\author{
Farshad Hedayati Dezfuli and M. Shahria Alam* \\ School of Engineering, The University of British Columbia, Kelowna, BC V1V1V7, Canada; \\ farshad.hedayati@alumni.ubc.ca \\ * Correspondence: shahria.alam@ubc.ca; Tel.: +1-250-807-9397; Fax: +1-250-807-9850 \\ Academic Editor: Mahmoud Reda Taha \\ Received: 6 November 2015; Accepted: 14 January 2016; Published: 27 January 2016
}

\begin{abstract}
Fiber-reinforced elastomeric isolators (FREIs) are a new type of elastomeric base isolation systems. Producing FREIs in the form of long laminated pads and cutting them to the required size significantly reduces the time and cost of the manufacturing process. Due to the lack of adequate information on the performance of FREIs in bonded applications, the goal of this study is to assess the performance sensitivity of $1 / 4$-scale carbon-FREIs based on the experimental tests. The scaled carbon-FREIs are manufactured using a fast cold-vulcanization process. The effect of several factors including the vertical pressure, the lateral cyclic rate, the number of rubber layers, and the thickness of carbon fiber-reinforced layers are explored on the cyclic behavior of rubber bearings. Results show that the effect of vertical pressure on the lateral response of base isolators is negligible. However, decreasing the cyclic loading rate increases the lateral flexibility and the damping capacity. Additionally, carbon fiber-reinforced layers can be considered as a minor source of energy dissipation.
\end{abstract}

Keywords: fiber-reinforced elastomeric isolator; carbon fiber fabric; manufacturing process; sensitivity analysis; effective horizontal stiffness; equivalent viscous damping

\section{Introduction}

Earthquake protective systems, categorized into active, semi-active, passive, and hybrid control mechanisms, are meant to protect structures (buildings and bridges) from the devastating effects of seismic excitations. Among these systems, rubber and sliding bearings as passive devices have been extensively used in structural engineering applications due to their easier operation where there is no need for external power supplies [1]. In rubber bearings, also called elastomeric isolators, alternating layers of rubber and reinforcement (e.g., steel shims) form a laminated pad. In sliding bearings, either flat or curved surfaces are in contact with each other in order to dissipate the energy through a frictional mechanism [2].

Modern elastomeric isolators, in which fiber fabric is used rather than steel shims, could facilitate the manufacturing process and improve the properties of elastomeric isolators [3,4]. In fact, by automating the fabrication process of FREIs, the production cost is noticeably reduced [3,5]. A big difference between these two types of reinforcement (fiber fabric and steel) is the flexibility of reinforcement. In contrast to the steel shims with a high flexural rigidity, fiber-reinforced sheets are completely flexible under bending [3]. This characteristic causes the FREI to show a rolling deformation (i.e., rollover deformation) under a lateral shear force. As a result, FREIs produce a lower amount of force in the transverse direction compared to steel-reinforced elastomeric isolators (SREIs). Therefore, FREI can be laterally deformed with a higher flexibility [6]. FRP composite materials have low density and a high strength-to-weight ratio. As a result, FREIs, which have superior performance, 
are significantly lighter than SREIs [5]. Reducing the weight of rubber bearings can significantly facilitate the manufacturing, shipping, handling and installation processes. Consequently, a wide range of applications (e.g., public, residential, and low-rise buildings) has been found for such modern and light isolators [7]. Kelly [4] studied the possibility of implementing FRP composite layers in rubber bearings. He clarified that FREI and SREI have comparable performances, and it is possible to produce such isolators with suitable mechanical properties. In an analytical study, Tsai and Kelly [8] investigated the flexibility of rectangular FREI in the form of infinite strip pads by focusing on the behavior of fibers and by considering the compressive and the bending stiffnesses. Results indicated that, when the shape factor, defined as a ratio of loaded area to force-free area of one elastomeric layer, increases, the FREI becomes stiffer, and, when a more flexible reinforcement is used, the stiffness decreases.

Moon et al. [5] fabricated FREIs consisting of different fibers (e.g., carbon, aramid, and glass) and compared them with SREIs. Experimental results revealed that FREIs are superior to SREIs in terms of vertical stiffness, effective horizontal stiffness, and equivalent viscous damping. They also observed that, compared to glass and aramid fibers, carbon fibers are more effective in increasing the vertical stiffness and equivalent viscous damping. Compression and cyclic shear tests conducted on FREIs by Dehghani Ashkezari et al. [9] showed that carbon fibers can dissipate energy through frictional movements. It was also determined that the vertical pressure can considerably affect the damping coefficient of FREI; however, it had negligible effect on the shear response of FREIs [9].

Experimental work along with an extensive finite element-based parametric study was carried out on FREIs made of glass-fiber fabrics and high damping rubber (HDR) in order to develop analytical models for such isolators [10]. In this regard, the effective horizontal and vertical stiffnesses of bearings as well as internal stresses in glass fibers and elastomeric layers were investigated by testing rubber bearings with different configurations (e.g., number and thickness of rubber and reinforced layers) under different loading and boundary conditions. In another experimental study, Zhang et al. [11] explored the mechanical properties of FREIs. Hysteresis of three FREIs having different thicknesses and numbers of elastomeric and fiber-reinforced layers subjected to vertical and cyclic shear loadings showed that the performance of FREIs is comparable to that of traditional steel-based isolators (SREIs).

Rubber bearings are either fixed in between the superstructure and the substructure using steel supporting plates (a bonded application) or mounted without any connecting mechanism and supporting plates (an unbonded application). With the purpose of studying the behavior of unbonded carbon-FREI, Toopchi-Nezhad et al. [6] performed experimental tests and observed that a rollover deformation occurs in the laminated pad due to a very low flexural rigidity of fiber-reinforced layers. As a consequence, the lateral flexibility of such unbonded C-FREI increased under cyclic shear displacements. In order to improve the low damping capacity and inadequate (very low) horizontal stiffness of such rubber bearings, they suggested that high damping rubber or supplementary elements can be used. The rollover deformation in unbonded FREIs can lead to an instability of the isolator (i.e., roll-out instability) if the resisting moment due to vertical loads (mainly weight of the superstructure) is lower than the overturning moment due to the horizontal forces (e.g., seismic loading). Pauletta et al. [12] were able to develop and validate a model for predicting the roll-out instability in unbonded fiber-reinforced elastomeric bearings.

Focusing on the compressive behavior of unbonded elastomeric bearings, Van Engelen et al. [13] explored the effect of geometric modifications on the vertical stiffness and the compressive modulus of rectangular FREIs. They validated a three-dimensional finite element model using experimental results and performed a parametric study. They observed that the vertical performance degrades with both interior and exterior modifications, but it is more sensitive to the exterior modification. The modifications were meant to improve the performance of the unbonded FREIs in the horizontal direction. Further experimental and numerical studies were performed on the lateral behavior of unbonded FREIs with different geometries [14]. It was observed that the considered geometry modifications could reduce the effective horizontal stiffness and enhance the damping properties of unbonded isolators. 
In addition to experimental work, several analytical studies have been done to describe the behavior of fiber-reinforced bearing pads under bending, compression, and shear. Russo et al. [15] proposed a geometric model to predict the deformation of fiber-reinforced pads (unbonded applications) under shear and compression. They carried out experimental tests on a number of specimens with different types of rubber (e.g., low and high damping neoprene), various reinforcements (e.g., bi-directional and quadri-directional carbon fiber fabrics), and different shape factors in order to present an expression for the lateral stiffness of the fiber-reinforced elastomeric isolators. Al-Anany and Tait [16] conducted a finite element-based numerical investigation on the compressive and rotational responses of bonded and unbonded FREIs by applying vertical and rotational deformations. The maximum applied pressure and rotation were $10 \mathrm{MPa}$ and 2.86 degrees, respectively. They validated the numerical results with analytical "pressure solution" approach and concluded that bonded and unbonded bearings have similar vertical behaviors, while bonded isolators can undergo larger rotational deformations. In addition, it was found that, in unbonded cases, the tensile stress demand on elastomer is negligible, and the tensile/compressive strain demand on the fiber reinforced layers is noticeably lower.

Based on experimental tests and through a parametric study, Hedayati Dezfuli and Alam [17] examined the effect of mechanical and physical properties (e.g., shear modulus and thickness of elastomer) on the response of the scaled size C-FREIs in bonded applications. Findings revealed that the equivalent viscous damping and the effective horizontal stiffness are very sensitive to the shear modulus of the elastomer and the vertical stiffness is sensitive to the shape factor. In another experimental study, Hedayati Dezfuli and Alam [18] manufactured bonded carbon fiber-reinforced bearing pads in a cold vulcanization process in order to investigate the effectiveness of the fabrication process and the performance of bonded C-FREIs in vertical and horizontal directions. They observed that, at $100 \%$ shear-strain amplitude, a partial debonding occurs between exterior rubber layers and supporting plates due to the rollover deformation. This phenomenon did not lead to a malfunction in the bearing pads; however, they stated that a more comprehensive work needs to be performed on full size specimens by conducting three-dimensional excitation tests with extreme loading conditions.

The objective of this study is to experimentally assess the performance sensitivity of $1 / 4$ scale C-FREIs, which are fabricated through a fast and simple process (cold-vulcanization), for bonded applications. A schematic cross-section view of C-FREIs is plotted in Figure 1. Based on the work done by Hedayati and Alam [18], the main motivation is the lack of adequate information on the response sensitivity of bonded FREIs that are manufactured in the presented process. This preliminary study is a complementary part of the work that these authors previously performed. The effect of different parameters, including the number of rubber layers, the thickness of carbon fiber fabric, the vertical pressure, and the rate of lateral cyclic displacements, is investigated on the horizontal operational characteristics (e.g., effective horizontal stiffness and equivalent viscous damping) of the C-FREIs. Here, it should be noted that the sensitivity of vertical characteristics (vertical stiffness and compressive modulus) have been experimentally studied by Hedayati and Alam. By fabricating rectangular laminated pads, made of alternating layers of rubber and bi-directional carbon fiber fabrics, the time and the cost of the manufacturing process as well as the total weight of rubber bearings are reduced. The sensitivity analyses are performed by conducting pressure and rate sensitivity tests. In the analyses, the shear hysteretic response of C-FREIs is evaluated in order to calculate the effective horizontal stiffness and the equivalent viscous damping. 


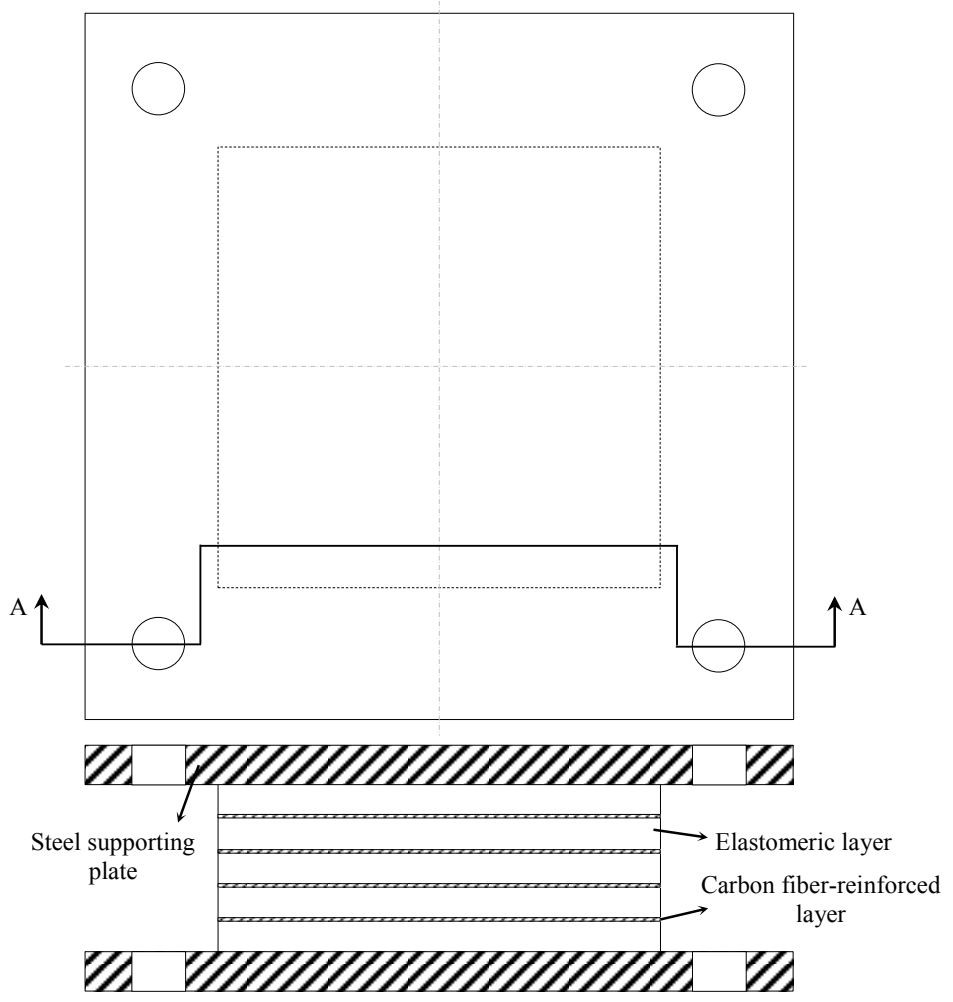

Figure 1. Schematic cross section view of C-FREIs.

\section{Manufacturing Test Specimens}

Six 1/4 scale C-FREIs were manufactured using the commercial high-quality neoprene with a hardness of 55 Shore A and a minimum tensile strength of $17 \mathrm{MPa}$ [19], bi-directional carbon fiber fabrics (orientations $0 / 90^{\circ}$ ) with a tensile strength of $4413 \mathrm{MPa}$ [20], and steel supporting plates. All specimens have identical widths and lengths $(70 \mathrm{~mm}$ by $70 \mathrm{~mm}$ ) but with different numbers and thicknesses of elastomeric and reinforcement layers. The total height of C-FREIs increases from $19.1 \mathrm{~mm}$ to $41.8 \mathrm{~mm}$. The shape factor, $S$, is either 5.8 or 11.7 for six C-FREIs. Table 1 demonstrates the geometric properties of the manufactured rubber bearings.

Table 1. Physical and geometric properties of FREIs.

\begin{tabular}{cccccccccc}
\hline C-FREI & $\begin{array}{c}\text { Plan Size of } \\
\text { Supporting Plates } \\
(\mathbf{m m} \times \mathbf{m m})\end{array}$ & $\begin{array}{c}\text { Plan Size of } \\
\text { Reinforcement } \\
(\mathbf{m m} \times \mathbf{m m})\end{array}$ & $\boldsymbol{H} \mathbf{( m m )}$ & $\boldsymbol{t}_{\boldsymbol{s}}(\mathbf{m m})$ & $\boldsymbol{t}_{\boldsymbol{e}} \mathbf{( m m )}$ & $\boldsymbol{t}_{f} \mathbf{( m m )}$ & $\boldsymbol{n}_{e}$ & $\boldsymbol{n}_{f}$ & $\boldsymbol{S}$ \\
\hline $\mathrm{A} 1$ & $150 \times 150$ & $70 \times 70$ & 26.5 & 6.35 & 1.5 & 0.25 & 8 & 7 & 11.7 \\
$\mathrm{~B} 1$ & $150 \times 150$ & $70 \times 70$ & 33.5 & 6.35 & 1.5 & 0.25 & 12 & 11 & 11.7 \\
$\mathrm{~A} 3$ & $150 \times 150$ & $70 \times 70$ & 40.5 & 6.35 & 1.5 & 0.25 & 16 & 15 & 11.7 \\
$\mathrm{~B} 4$ & $150 \times 150$ & $70 \times 70$ & 42.4 & 6.35 & 1.5 & 0.25 & 17 & 16 & 11.7 \\
$\mathrm{D} 1$ & $150 \times 150$ & $70 \times 70$ & 36.7 & 6.35 & 3 & 0.50 & 7 & 6 & 5.8 \\
$\mathrm{E} 1$ & $150 \times 150$ & $70 \times 70$ & 38.2 & 6.35 & 3 & 0.75 & 7 & 6 & 5.8 \\
\hline
\end{tabular}

Notes: $H$ : total height of C-FREI; $t_{s}$ : thickness of supporting plates; $t_{e}$ : thickness of elastomeric layers; $t_{f}$ : thickness of carbon fiber fabrics; $n_{e}$ : number of elastomeric layers; $n_{f}$ : number of fiber-reinforced layers; S: shape factor.

Rubber cement is a cold bonding compound made of elastic polymers (typically latex). It is used to attach elastomeric layers to bi-directional carbon fiber fabrics. In the curing process, laminated pads were subjected to a uniform pressure of $4 \mathrm{MPa}$ for $24 \mathrm{~h}$ at the room temperature without using a mold. According to the rubber cement manufacturer's instructions, $70 \%$ to $80 \%$ of the bond strength 
was achieved during $24 \mathrm{~h}$ at the room temperature, and the rest is developed over the next 14 days. Then, the laminated pads in the form of long strips were cut to the required size (70 $\mathrm{mm}$ by $70 \mathrm{~mm}$ ) using a water-jet machine in order to create very smooth side surfaces and to prevent delamination between layers during the cutting process. Finally, in order to improve the bonding between layers and prevent premature delamination that might occur during shipping, installation, or testing, side faces were coated with two layers of adhesive (rubber cement).

The same bonding compound was used to attach steel supporting plates to the C-FREI. Figure 2 shows the reinforcement layer, which is sandwiched between rubber layers before bonding, the bonding compound, and the adhesive agent used in preparing C-FREIs.

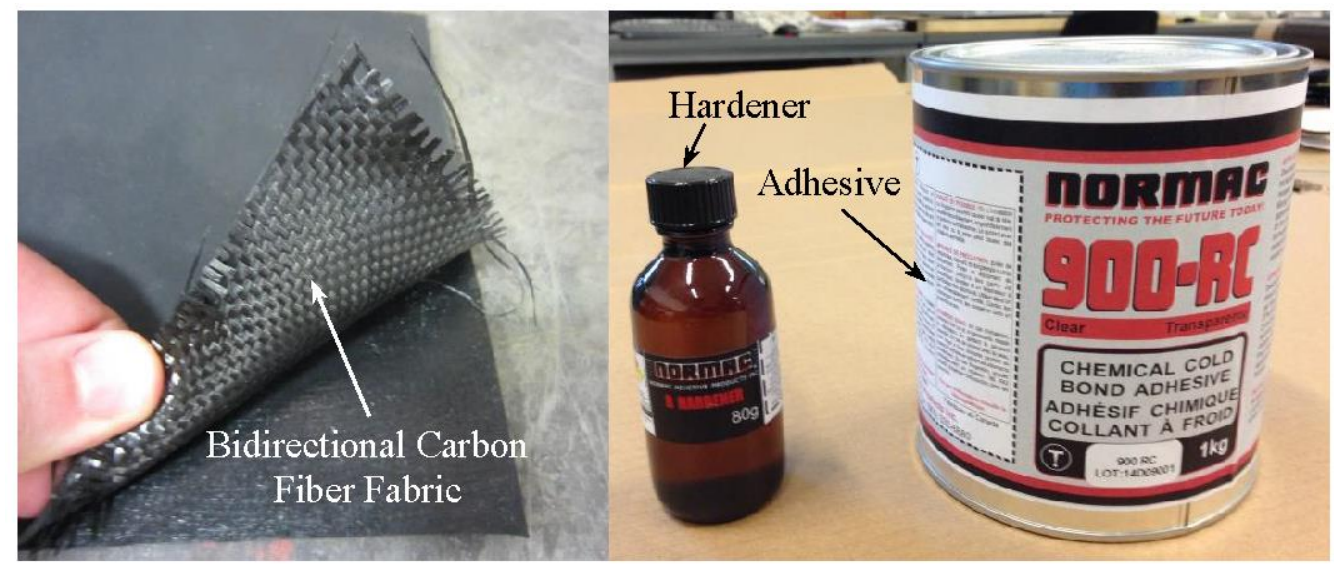

Figure 2. Reinforcement and cold bonding compound used in C-FREIs.

The reinforcement was a $12 \times 12$ (i.e., count of warp and fill fibers) plain weave bi-directional carbon fiber fabric with a thickness of 0.009 in and a weight of $0.196 \mathrm{~kg} / \mathrm{m}^{2}$. The fabric was woven from $3 \mathrm{~K}$ carbon stands with a tensile modulus of $230 \mathrm{GPa}$ [20]. Figure 3 depicts the plan and elevation views of carbon fiber fabric used as reinforcement in C-FREIs.
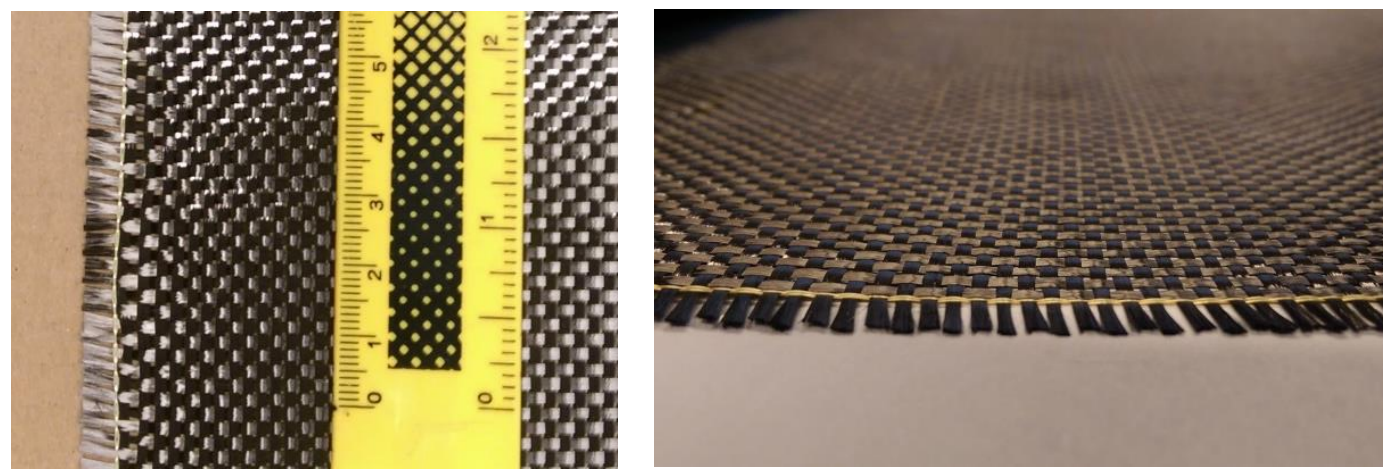

Figure 3. Schematics of plan and elevation views of bi-directional carbon fiber fabrics.

\section{Experimental Tests}

In order to study the behavior of FREIs in the horizontal direction, changes of effective horizontal stiffness and equivalent viscous damping were measured. In lateral cyclic tests, shear displacements are applied by a horizontal hydraulic jack connected to the lower steel supporting plate, while the upper steel supporting plate is fixed under a constant compressive load. The test setup is shown in Figure 4. 


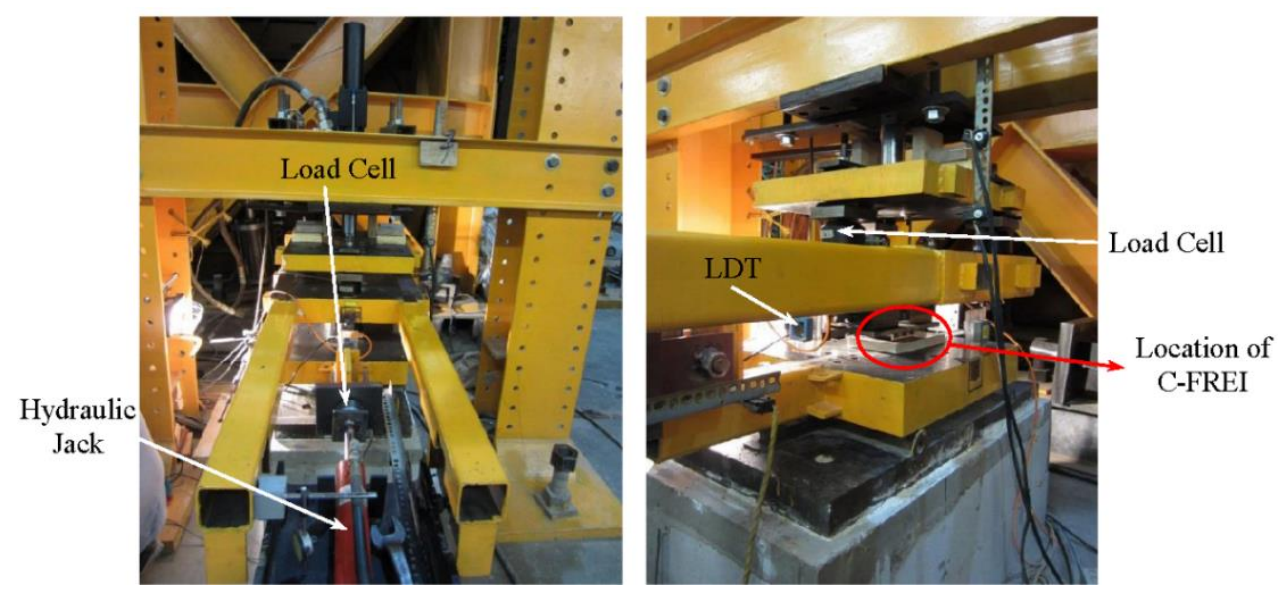

Figure 4. Test equipment used for testing C-FREIs.

The effect of vertical pressure, horizontal cyclic rate, number of elastomeric layers, and thickness of fiber-reinforced layers were investigated on the lateral behavior of bearings through two series of tests, categorized as follows.

\subsection{Pressure Sensitivity Test}

The objective of the pressure sensitivity test is to evaluate the effect of vertical pressure on the operational characteristics including the effective horizontal stiffness and the equivalent viscous damping of the base isolator. The horizontal stiffness is a measure of the lateral flexibility, and the equivalent viscous damping represents the capability of the device in dissipating the earthquake's energy. In order to explore the effect of pressure on the efficiency of the device, different cyclic tests were performed by changing the vertical compressive load (1 MPa, $2 \mathrm{MPa}$, and $3 \mathrm{MPa})$, while other parameters are kept constant. Cyclic tests were performed by simultaneously applying the vertical pressure (in load control mode) and the lateral cyclic displacements (in displacement control mode).

In each test, while the C-FREI was subjected to a constant vertical pressure, $P$, the cyclic horizontal displacements were applied. At each amplitude of horizontal deflection including $25 \% t_{r}, 50 \% t_{r}$, and $100 \% t_{r}\left(t_{r}\right.$ is the total thickness of rubber layers), three fully reversed sinusoidal cycles were applied at constant horizontal rate of $V_{H}=20 \mathrm{~mm} / \mathrm{s}$. Variations of vertical pressure and cyclic horizontal displacements versus time are demonstrated in Figure $5 \mathrm{a}, \mathrm{b}$, respectively. It should be noted that, at shear-strain levels higher than 100\%, unrecoverable deformations occurred. As a consequence, in all tests, the shear strain was limited to a range of $0 \%$ to $100 \%$.
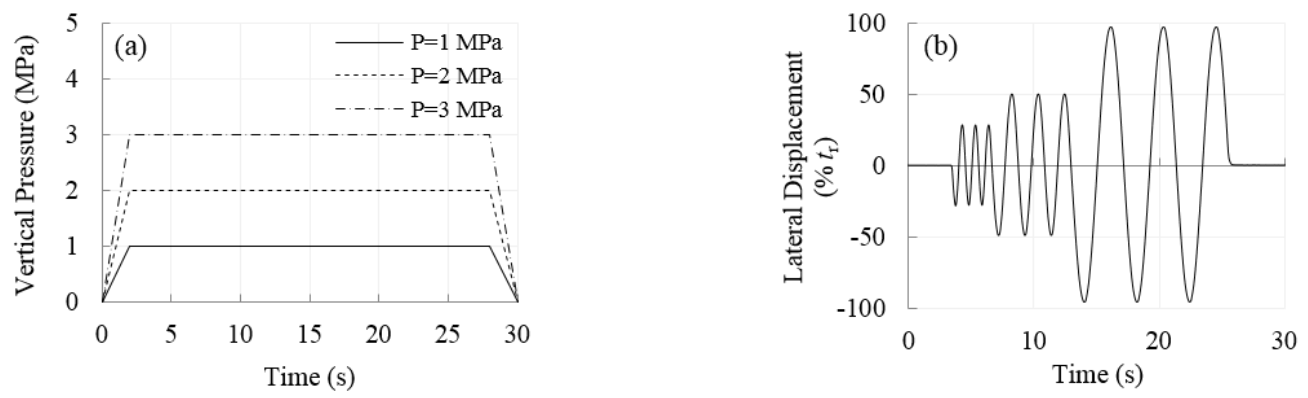

Figure 5. Input loadings in cyclic tests: (a) variation of vertical pressure over time; (b) cyclic displacements $\left(25 \% t_{r}\right.$ to $\left.100 \% t_{r}\right)$. 
The effective horizontal stiffness of C-FREIs, $K_{\text {Heff }}$, at each shear-strain amplitude $(\gamma)$, was calculated according to Equation (1) [21,22].

$$
K_{H e f f}(\gamma)=\frac{F_{\max }-F_{\min }}{\Delta_{\max }-\Delta_{\min }}
$$

where $\Delta_{\max }$ and $\Delta_{\min }$ are the peak lateral displacements and $F_{\max }$ and $F_{\min }$ are the peak shear forces, at each shear-strain amplitude. The equivalent viscous damping of rubber bearing, $\beta$, is defined as a ratio of the dissipated energy to the elastic energy restored in the C-FREI [23].

$$
\beta=\frac{1}{4 \pi} \frac{U_{d}}{U_{e}}
$$

in which $U_{d}$ is the energy dissipated per cycle and equals to the area inside the lateral force-deflection hysteresis curve in each cycle and $U_{e}$ is the energy restored in the rubber bearing measured according to Equation (3) [7].

$$
U_{e}=\frac{1}{2} K_{H e f f} \Delta_{\text {avg }}^{2}
$$

where $\Delta_{\text {avg }}=\left(\Delta_{\max }+\left|\Delta_{\min }\right|\right) / 2$.

\subsection{Rate Sensitivity Test}

In the rate sensitivity test, the influence of lateral cyclic rate on the performance of C-FREIs was investigated. Cyclic tests are conducted by changing the rate of the cyclic horizontal displacements $(20 \mathrm{~mm} / \mathrm{s}, 30 \mathrm{~mm} / \mathrm{s}$, and $75 \mathrm{~mm} / \mathrm{s}$ ) while the pressure and the lateral displacement amplitude remain constant. The procedure of performing the tests was the same as the horizontal cyclic tests. While the C-FREI was under a constant vertical pressure of $1.5 \mathrm{MPa}$, the cyclic horizontal displacements were applied. At a lateral amplitude of $50 \% t_{r}$, three fully reversed sinusoidal cycles were applied. Variation of cyclic horizontal displacements versus time is depicted in Figure 6 for three different rates.
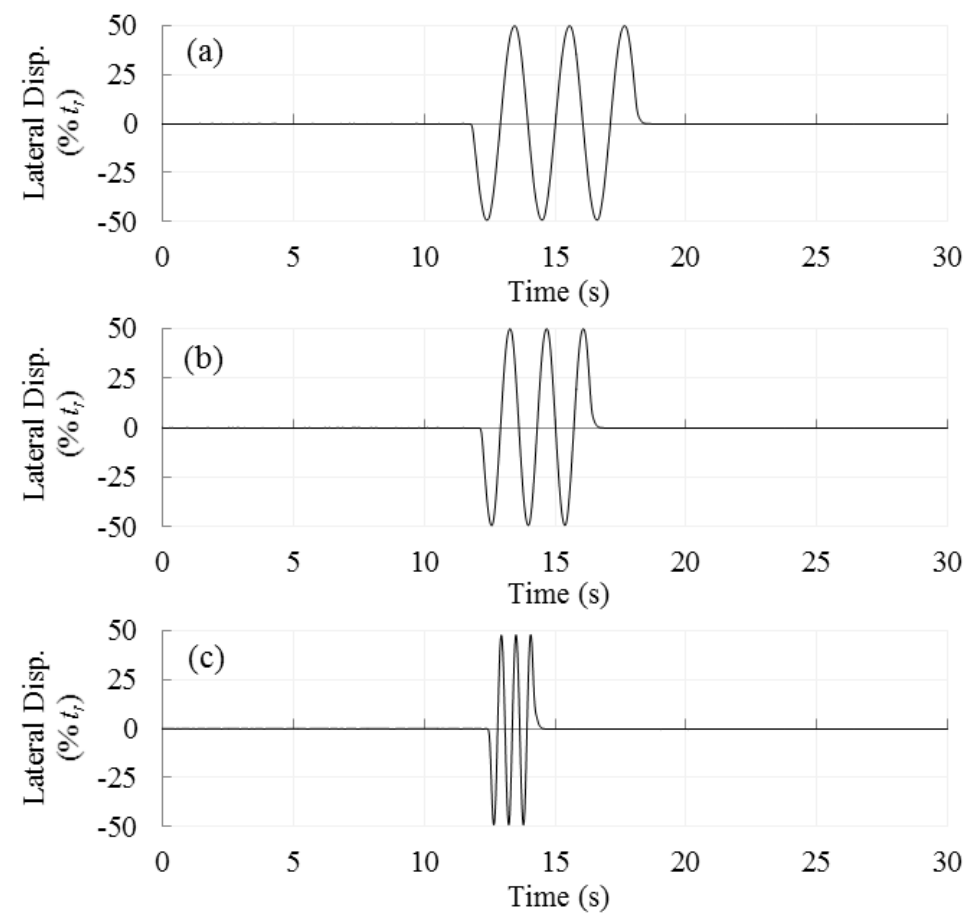

Figure 6. Lateral cyclic displacement $\left(50 \% t_{\mathrm{r}}\right)$ for three different rates; (a) $20 \mathrm{~mm} / \mathrm{s}$; (b) $30 \mathrm{~mm} / \mathrm{s}$; (c) $75 \mathrm{~mm} / \mathrm{s}$. 
In a sinosoidal harmonic motion, the amplitude of the linear velocity, $V$, is related to the amplitude of the displacement using the angular frequency, $\omega$, according to Equation (4). Since $\omega$ can be expressed in terms of cyclic frequency, $f,(\omega=2 \pi f)$, and the amplitude of cyclic lateral displacement, $A$, is equal to the shear strain, $\gamma$, multiplied by the total thickness of rubber layers, $t_{r},\left(A=\gamma t_{r}\right)$, the lateral cyclic frequency, $f_{H}$, at $100 \%$ shear strain, can be calculated from the horizontal rate, $V_{\mathrm{H}}$, according to Equation (5).

$$
\begin{aligned}
V & =\omega A \\
f_{H} & =\frac{V_{H}}{2 \pi t_{r}}
\end{aligned}
$$

\section{Results and Discussion}

Two operational characteristics of C-FREIs in the lateral direction (the effective horizontal stiffness and the equivalent viscous damping) are evaluated through sensitivity analyses.

\subsection{Effect of Vertical Pressure}

For each C-FREI, three lateral force-deflection hysteresis curves are presented for three vertical pressures. Figure 7 shows the shear behavior of the rubber bearings at different shear strains and pressure levels.

When FREIs A3 and B4 are subjected to a vertical pressure of $1 \mathrm{MPa}$, the first cycle of the lateral loading at $50 \%$ and $100 \%$ shear-strain levels is different from the second and third cycles. This fact is due to the delamination that occurs in the exterior layers of the laminated pad after the first cycle. As a result, the slope of the lateral force-deflection curve decreases. Since the total number of elastomeric layers in A3 and B4 is higher than that of four other C-FREIs (see Table 1), the possibility of debonding of the rubber layer from either the steel supporting plate or the reinforcement noticeably increases. Such a behavior is not observed when the pressure increases to $2 \mathrm{MPa}$ and $3 \mathrm{MPa}$ because the vertical load postpones the delamination (debonding).

The effective horizontal stiffness and the equivalent viscous damping were measured using Equations (1) and (2), respectively. The average of three hysteresis loops, at each displacement, is calculated and the results are listed in Table 2.

Table 2. Effective horizontal stiffness and equivalent viscous damping of C-FREIs at different

\begin{tabular}{|c|c|c|c|c|c|c|c|}
\hline \multirow{2}{*}{ C-FREI } & \multirow{2}{*}{$P(\mathrm{MPa})$} & \multicolumn{3}{|c|}{$K_{H}(\mathbf{k N} / \mathbf{m m})$} & \multicolumn{3}{|c|}{$\beta(\%)$} \\
\hline & & 1 & 2 & 3 & 1 & 2 & 3 \\
\hline \multirow{3}{*}{ A1 } & 25 & 0.375 & 0.380 & 0.375 & 11.7 & 11.9 & 11.7 \\
\hline & 50 & 0.287 & 0.289 & 0.287 & 10.3 & 10.4 & 10.3 \\
\hline & 100 & 0.239 & 0.240 & 0.239 & 9.1 & 9.2 & 9.1 \\
\hline \multirow{3}{*}{ B1 } & 25 & 0.226 & 0.244 & 0.233 & 13.0 & 13.0 & 13.2 \\
\hline & 50 & 0.177 & 0.188 & 0.181 & 12.6 & 12.3 & 12.5 \\
\hline & 100 & 0.128 & 0.141 & 0.137 & 12.7 & 11.9 & 11.6 \\
\hline \multirow{3}{*}{ D1 } & 25 & 0.203 & 0.211 & 0.203 & 11.1 & 11.0 & 11.1 \\
\hline & 50 & 0.165 & 0.169 & 0.165 & 10.3 & 10.2 & 10.3 \\
\hline & 100 & 0.132 & 0.132 & 0.132 & 9.3 & 9.3 & 8.9 \\
\hline \multirow{3}{*}{ E1 } & 25 & 0.212 & 0.223 & 0.212 & 11.6 & 11.4 & 11.6 \\
\hline & 50 & 0.170 & 0.176 & 0.170 & 10.5 & 10.3 & 10.5 \\
\hline & 100 & 0.135 & 0.136 & 0.135 & 9.7 & 9.7 & 9.8 \\
\hline \multirow{3}{*}{ A3 } & 25 & 0.209 & 0.171 & 0.165 & 12.5 & 12.6 & 12.6 \\
\hline & 50 & 0.153 & 0.132 & 0.128 & 11.2 & 11.6 & 11.7 \\
\hline & 100 & 0.095 & 0.096 & 0.094 & 13.2 & 11.2 & 11.2 \\
\hline \multirow{3}{*}{ B4 } & 25 & 0.213 & 0.173 & 0.166 & 12.8 & 12.9 & 13.1 \\
\hline & 50 & 0.158 & 0.133 & 0.129 & 11.4 & 11.8 & 12.0 \\
\hline & 100 & 0.099 & 0.099 & 0.097 & 12.3 & 10.7 & 10.9 \\
\hline
\end{tabular}
shear-strain amplitudes and vertical pressures. 


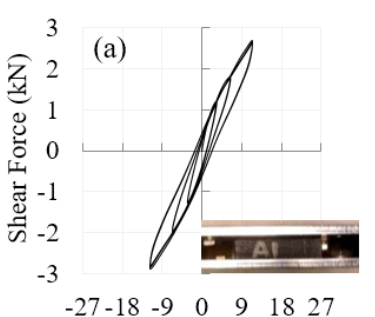

Lateral Disp. (mm)
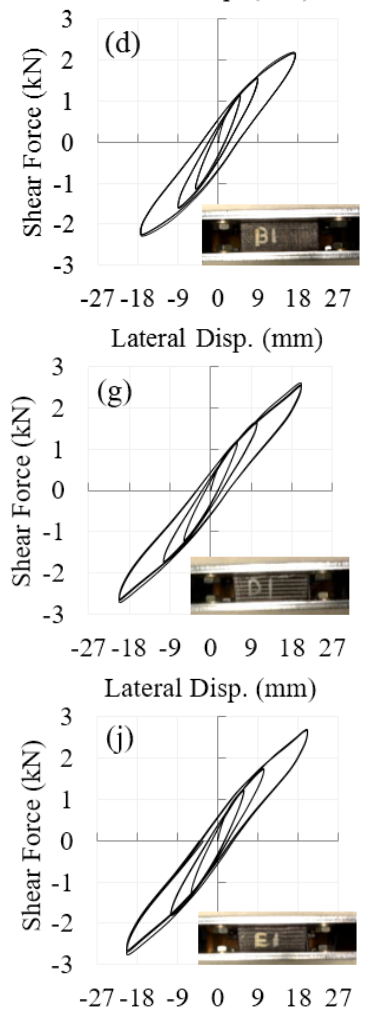

Lateral Disp. (mm)
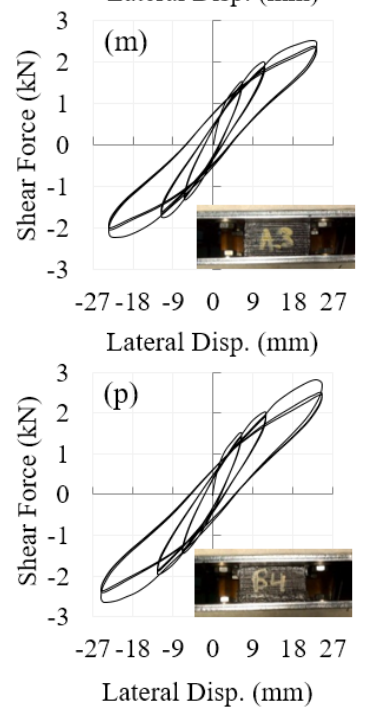
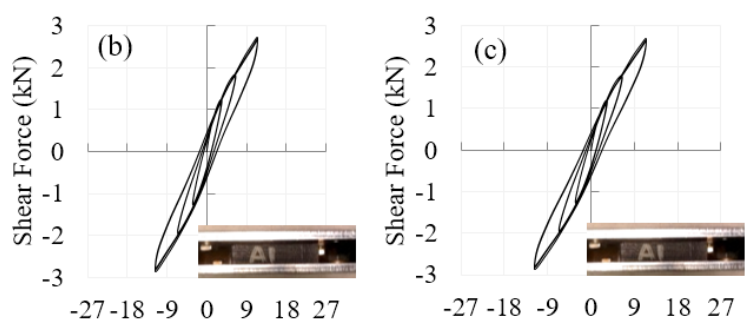

Lateral Disp. (mm)
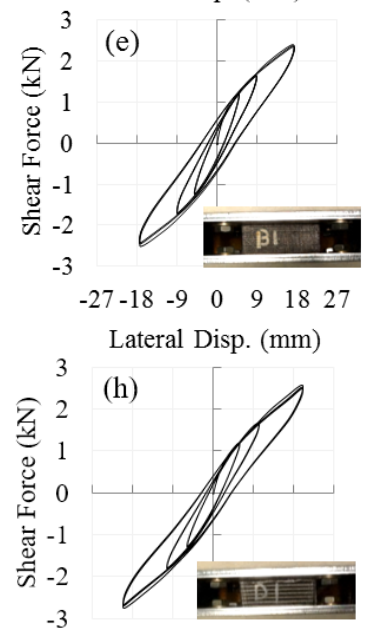

$\begin{array}{llllll}-27-18 & -9 & 0 & 9 & 18 & 27\end{array}$

Lateral Disp. (mm)

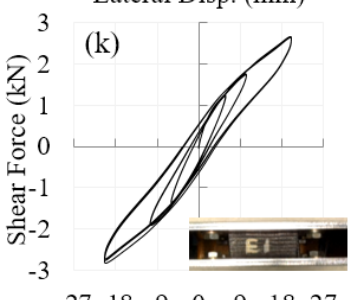

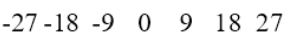
Lateral Disp. (mm)

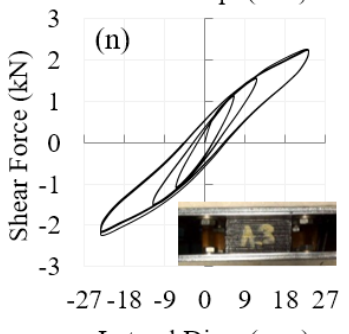

Lateral Disp. (mm)

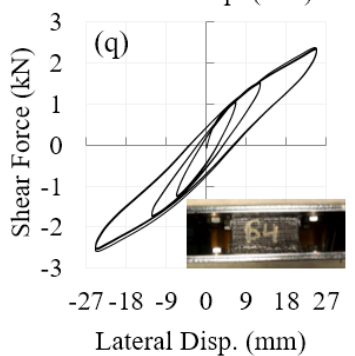

Lateral Disp. (mm)
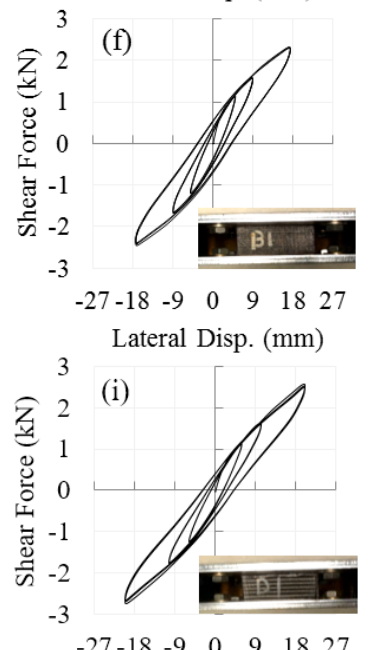

$\begin{array}{cccccc}-27-18 & -9 & 0 & 9 & 18 & 27\end{array}$

Lateral Disp. (mm)

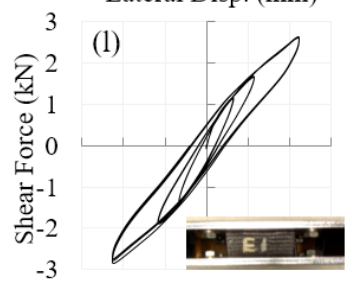

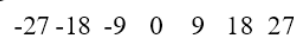

Lateral Disp. (mm)
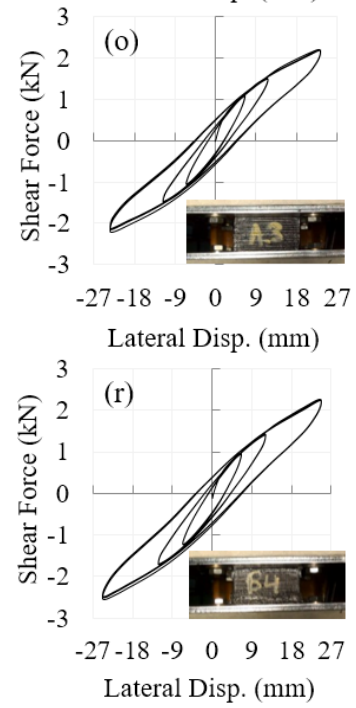

Figure 7. Hysteresis of C-FREIs under different vertical pressures $(P=1,2$, and $3 \mathrm{MPa})$ and shear strains ( $\gamma=25 \%, 50 \%$, and 100\%); (a) A1 under 1MPa; (b) A1 under 2MPa; (c) A1 under 3MPa; (d) B1 under 1MPa; (e) B1 under 2MPa; (f) B1 under 3MPa; (g) D1 under 1MPa; (h) D1 under 2MPa; (i) D1 under 3MPa; (j) E1 under 1MPa; (k) E1 under 2MPa; (1) E1 under 3MPa; (m) A3 under 1MPa; (n) A3 under 2MPa; (o) A3 under 3MPa; (p) B4 under 1MPa; (q) B4 under 2MPa; (r) B4 under 3MPa. 
By comparing the hysteretic responses, it can be observed that FREI-A1, with the lowest thickness of rubber layers, has the maximum amount of effective horizontal stiffness. This behavior shows that the elastomeric layers mainly contribute to the lateral flexibility of the device. On the other hand, the area inside the hysteresis loops, which represents the energy dissipated by the device, increases for C-FREIs A3 and B4 having higher total thicknesses of elastomer $\left(t_{r}\right)$.

\subsubsection{Effective Horizontal Stiffness}

At each shear-strain amplitude $(25 \%, 50 \%$, and $100 \%)$, the effective horizontal stiffness of each C-FREI is calculated under three vertical pressures $(1,2$, and $3 \mathrm{MPa})$. Figure 8 shows that the vertical pressure has a negligible influence on the lateral flexibility of the C-FREIs regardless of the shear-strain amplitude. At low lateral displacements $(\gamma=25 \%)$, minor changes are observed in the horizontal stiffness as the pressure increases. However, at 100\% shear strain, the fluctuation of the effective horizontal stiffness almost vanishes. This characteristic demonstrates that the manufactured C-FREIs are almost insensitive to the vertical pressure. This insensitivity is due to material properties of elastomer (neoprene) used in the C-FREIs since the lateral behavior of the isolators is mainly governed by the rubber layers. Compared to the high damping rubber, which has a highly nonlinear behavior depending on the loading and environmental conditions, the neoprene has a low sensitivity to the vertical pressure. Hence, almost the same responses are observed for C-FREIs when the vertical pressure changes.
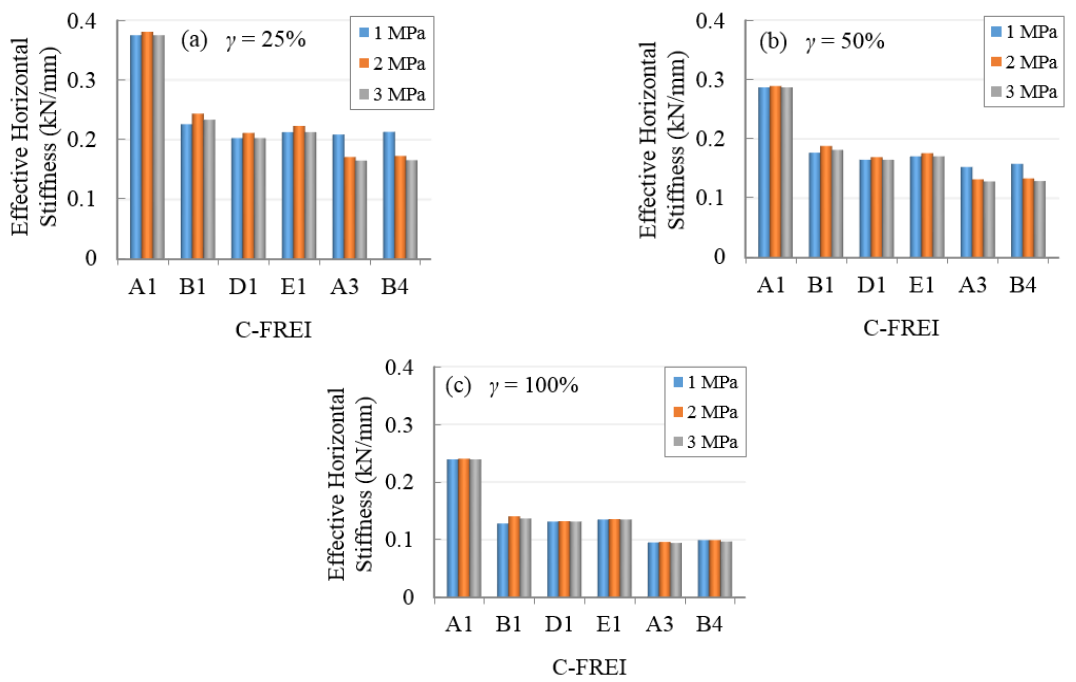

Figure 8. Effective horizontal stiffness of C-FREIs under different vertical pressures (1, 2, and $3 \mathrm{MPa})$ and shear strains of (a) $25 \%$; (b) $50 \%$; and (c) $100 \%$.

At $25 \%$ and $50 \%$ shear strains, the effective horizontal stiffnesses of A3 and B4 are reduced when the vertical pressure increases from $1 \mathrm{MPa}$ to $2 \mathrm{MPa}$. The reason is that these two C-FREIs have higher lateral flexibilities under low vertical pressure $(1 \mathrm{MPa})$ due to their higher thicknesses of rubber layers compared to other bearings.

\subsubsection{Equivalent Viscous Damping}

The equivalent viscous damping of rubber bearing is the second characteristic considered in this study. Here, results are presented in three bar charts; each plot corresponds to one shear-strain amplitude where the vertical pressure increases from $1 \mathrm{MPa}$ to $3 \mathrm{MPa}$ (Figure 9).

By increasing the pressure, the equivalent viscous damping changes between $9.1 \%$ and $13.2 \%$ (see Table 2). With respect to the magnitude of the damping coefficients, the variation of this parameter is negligible. When the vertical pressure changes, at low shear-strain levels ( $25 \%$ and $50 \%)$, the equivalent 
viscous damping remains almost constant (see Figure 9a,b). However, at 100\% shear strain (Figure 9c), the damping coefficient of $\mathrm{B} 1, \mathrm{~A} 3$, and $\mathrm{B} 4$ encounters a slight reduction when the vertical pressure increases from $1 \mathrm{MPa}$ to $2 \mathrm{MPa}$. The reason is that these three C-FREIs have higher capabilities in dissipating the energy under low vertical loads $(1 \mathrm{MPa})$ due to their higher number of rubber layers compared to other bearings. As a result of using the commercial high-quality neoprene, known to be the primary source of energy dissipation, the manufactured C-FREIs have a higher damping capacity compared to low-damping (unfilled) rubber bearings. However, compared to high damping rubber bearings, the C-FREIs have a lower capacity.
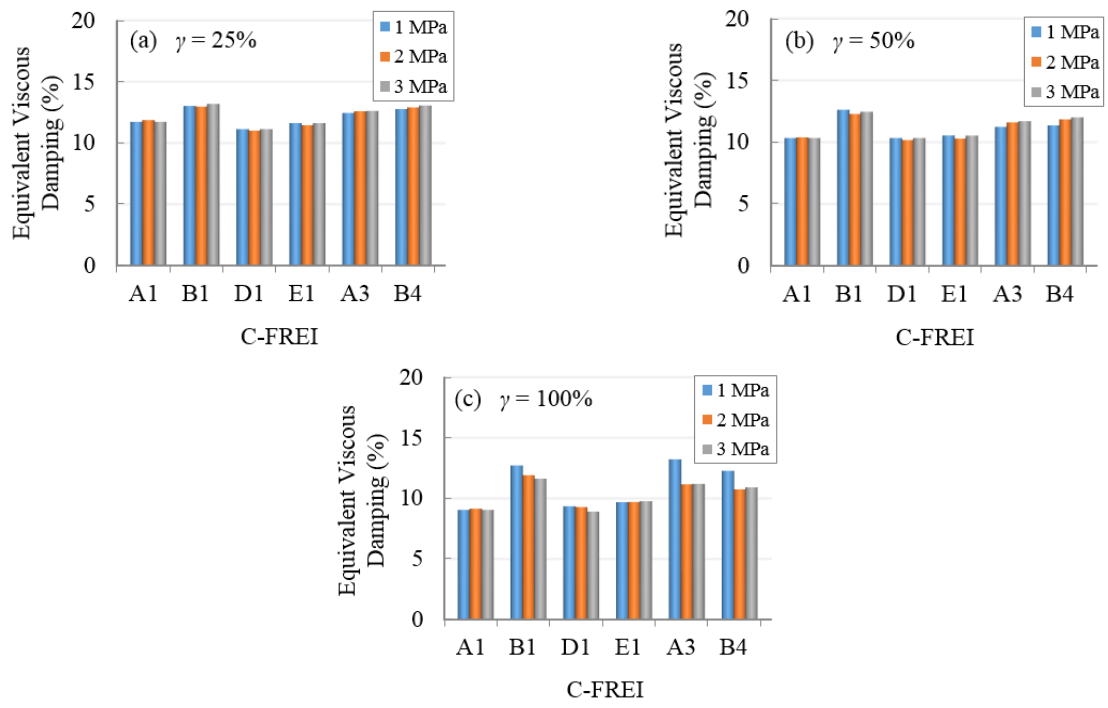

Figure 9. Equivalent viscous damping of C-FREIs under different vertical pressures $(1,2$, and $3 \mathrm{MPa})$ and shear strains of (a) $25 \%$; (b) $50 \%$; and (c) $100 \%$.

\subsection{Effect of Lateral Cyclic Rate}

Different earthquakes with different magnitudes and frequency content hit the base-isolated structures. In such a situation, investigating the effect of lateral cyclic rate or frequency on the performance of the elastomeric bearings will be of great interest. Based on the test procedure defined for the rate sensitivity experiment, the hysteretic shear response at $50 \%$ shear strain are illustrated for six elastomeric isolators (Figure 10). For each C-FREI, three hysteresis curves are plotted in one figure in order to compare behaviors of the fiber-reinforced rubber bearings by changing the cyclic rate, $V_{H}$.

The effective horizontal stiffness and the equivalent viscous damping were calculated at different lateral cyclic rates, $V_{H}$, as listed in Table 3. It should be mentioned that the horizontal frequency, $f_{H}$, was computed according to Equation (5). By considering a constant shear strain (e.g., 100\%) and a constant lateral cyclic rate, the horizontal frequency changes for different elastomeric bearings since C-FREIs have different total thicknesses of elastomer $\left(t_{r}\right)$.
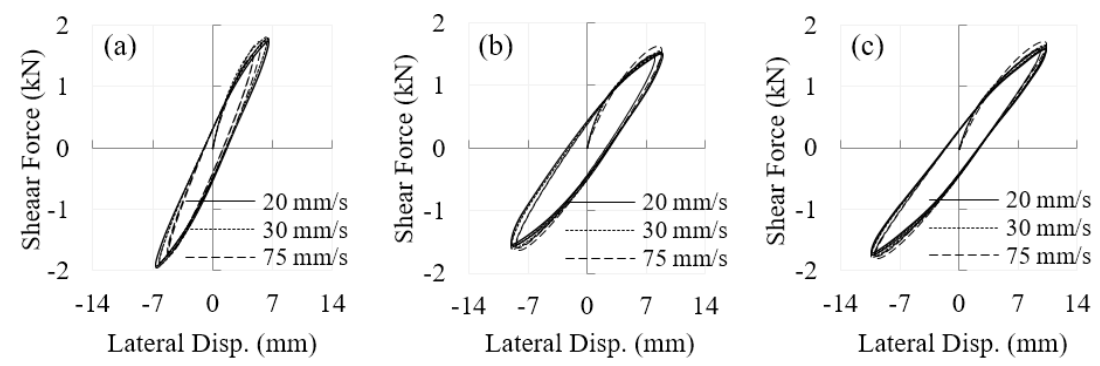

Figure 10. Cont. 

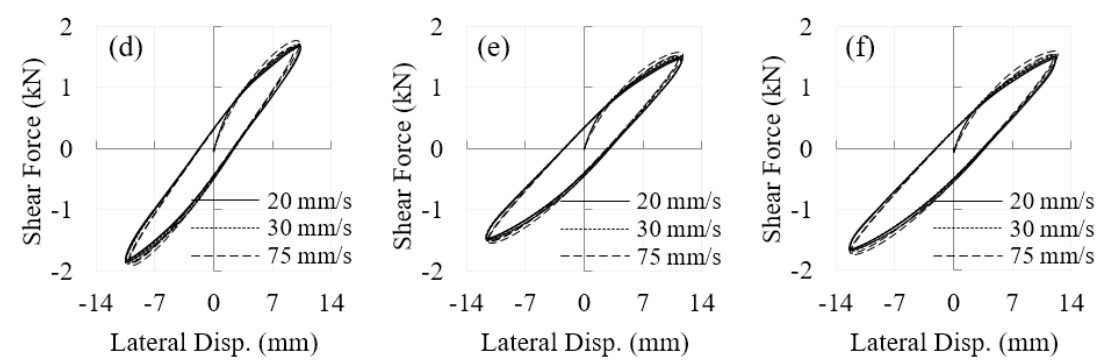

Figure 10. Hysteresis of C-FREIs at different lateral rates $(20,30$, and $75 \mathrm{~mm} / \mathrm{s})$ and $50 \%$ shear strain; (a) A1; (b) B1; (c) D1; (d) E1; (e) A3; (f) B4.

Table 3. Effective horizontal stiffness and equivalent viscous damping of C-FREIs at different lateral cyclic rates.

\begin{tabular}{|c|c|c|c|c|}
\hline C-FREI & $V_{H}(\mathrm{~mm} / \mathrm{s})$ & $f_{H}(\mathrm{~Hz})$ & $K_{H}(\mathbf{k N} / \mathbf{m m})$ & $\beta(\%)$ \\
\hline \multirow{3}{*}{ A1 } & 20 & 0.27 & 0.284 & 10.5 \\
\hline & 30 & 0.40 & 0.293 & 10.5 \\
\hline & 75 & 1.00 & 0.317 & 9.9 \\
\hline \multirow{3}{*}{ B1 } & 20 & 0.18 & 0.171 & 14.1 \\
\hline & 30 & 0.27 & 0.176 & 13.5 \\
\hline & 75 & 0.66 & 0.187 & 12.2 \\
\hline \multirow{3}{*}{ D1 } & 20 & 0.15 & 0.165 & 10.3 \\
\hline & 30 & 0.23 & 0.167 & 10.1 \\
\hline & 75 & 0.57 & 0.174 & 9.6 \\
\hline \multirow{3}{*}{ E1 } & 20 & 0.15 & 0.171 & 10.6 \\
\hline & 30 & 0.23 & 0.173 & 10.5 \\
\hline & 75 & 0.57 & 0.181 & 10.1 \\
\hline \multirow{3}{*}{ A3 } & 20 & 0.13 & 0.128 & 12.2 \\
\hline & 30 & 0.20 & 0.130 & 11.9 \\
\hline & 75 & 0.50 & 0.134 & 11.5 \\
\hline \multirow{3}{*}{ B4 } & 20 & 0.12 & 0.129 & 12.1 \\
\hline & 30 & 0.19 & 0.131 & 11.8 \\
\hline & 75 & 0.47 & 0.135 & 11.4 \\
\hline
\end{tabular}

\subsubsection{Effective Horizontal Stiffness}

In order to determine whether or not the loading rate $\left(V_{H}\right)$ affects the horizontal stiffness of C-FREIs, lateral cyclic displacements with three different rates including $20 \mathrm{~mm} / \mathrm{s}, 30 \mathrm{~mm} / \mathrm{s}$, and $75 \mathrm{~mm} / \mathrm{s}$ were applied to the rubber bearings. The following bar chart compares this parameter at different rates (Figure 11).

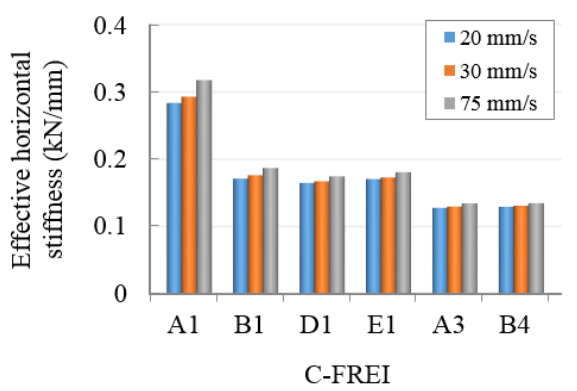

Figure 11. Effective horizontal stiffness of C-FREIs under different lateral cyclic rates (20, 30, and $75 \mathrm{~mm} / \mathrm{s}$ ) at $50 \%$ shear strain. 
For all C-FREIs, increasing the rate led to an increase in the effective horizontal stiffness. However, the amount of changes was negligible when the lateral rate was low (e.g., $20 \mathrm{~mm} / \mathrm{s}$ and $30 \mathrm{~mm} / \mathrm{s}$ ). By increasing the cyclic rate to $75 \mathrm{~mm} / \mathrm{s}$, a greater increase was observed in the lateral stiffness. In order to clarify this behavior, it can be stated that, when the rate of the lateral cyclic loading increases, the elastomeric layers are stiffened, and, as a result, the rubber bearings showed a lower flexibility in the horizontal direction.

\subsubsection{Equivalent Viscous Damping}

In contrast to the effective horizontal stiffness, the equivalent viscous damping decreased by increasing the lateral cyclic rate. This fact can be observed in Figure 12, which depicts the variation of the damping coefficient for each C-FREI by changing the loading rate. The flexibility of rubber layers was reduced at high lateral loading rates, and, as a result, the energy restored in the C-FREIs increased according to Equation (3). On the other hand, the capability of the device in dissipating the earthquake's energy degraded because the rubber layers were stiffened by increasing the lateral loading rate. Therefore, the equivalent viscous damping, which is proportional to the ratio of the dissipated energy to the restored energy (see Equation (2)), decreased by increasing the horizontal loading rate.

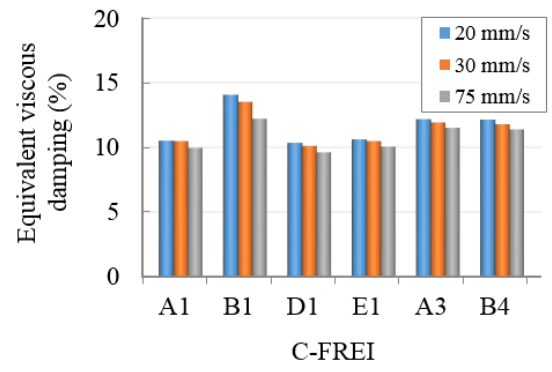

Figure 12. Equivalent viscous damping of C-FREIs under different lateral cyclic rates (20, 30, and $75 \mathrm{~mm} / \mathrm{s}$ ) at $50 \%$ shear strain.

\subsection{Effect of Number of Rubber Layers}

In order to study the effect of the number of rubber layers, $n_{e}$, on the response of C-FREIs, this parameter changed, while the thicknesses of elastomeric and fiber-reinforced layers were kept constant. C-FREIs A1, B1, and A3, with $n_{e}$ equals to 8, 12, and 16, respectively, were selected among six specimens (Table 1). Figure 13 illustrates the effect of the number of rubber layers on the effective horizontal stiffness and the equivalent viscous damping of C-FREIs. As expected, when the number of elastomeric layers increases, the lateral flexibility of the rubber bearings increased and the horizontal stiffness decreased. Figure 13a shows similar behaviors for three shear-strain levels.
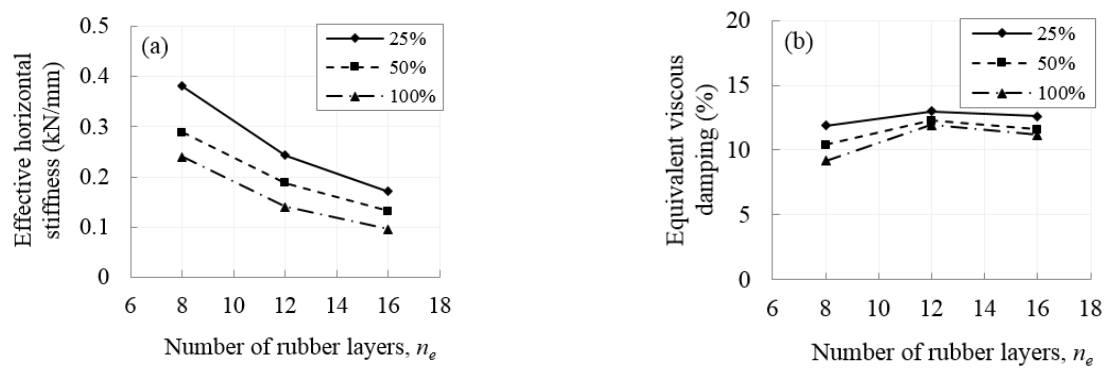

Figure 13. Effect of number of rubber layers on (a) effective horizontal stiffness and (b) equivalent viscous damping of C-FREIs at $25 \%, 50 \%$, and $100 \%$ shear strains. 
By increasing the number of rubber layers, the performance of the C-FREIs improves in terms of the damping capacity (Figure 13b). This behavior can be clearly observed when $n_{\mathrm{e}}$ changes from 8 to 12 . However, by increasing $n_{e}$ from 12 to 16 , the equivalent viscous damping is slightly reduced. The reason is that, when $n_{e}$ increases from 12 to 16 , both the restored elastic energy and the dissipated energy are increased, but the restored energy changes more than the dissipated energy. Therefore, the ratio of the restored energy to the dissipated energy, which denotes the equivalent viscous damping, decreases.

\subsection{Effect of Thickness of Fiber-reinforced Layers}

Among geometric properties considered in this study, only the thicknesses of reinforcement $\left(t_{f}\right)$ of C-FREIs D1 and E1 are different (see Table 1). For this reason, C-FREIs D1 and E1 were selected in order to perform a sensitivity analysis on the thickness of the carbon fiber fabrics. In D1 and E1, two and three layers of bi-directional carbon fiber fabrics were used, respectively. Since a single fiber fabric has a thickness of $0.25 \mathrm{~mm}$, the thickness of reinforcement in D1 and E1 was $0.50 \mathrm{~mm}$ and $0.75 \mathrm{~mm}$, respectively.

The effective horizontal stiffness of C-FREI-E1 was higher than that of D1. This difference vanished by increasing the lateral deflection (see Figure 14a). Increasing the thickness of reinforced layers decreased the lateral flexibility. The reason is that fiber-reinforced layers become stiffer when their thickness increases.
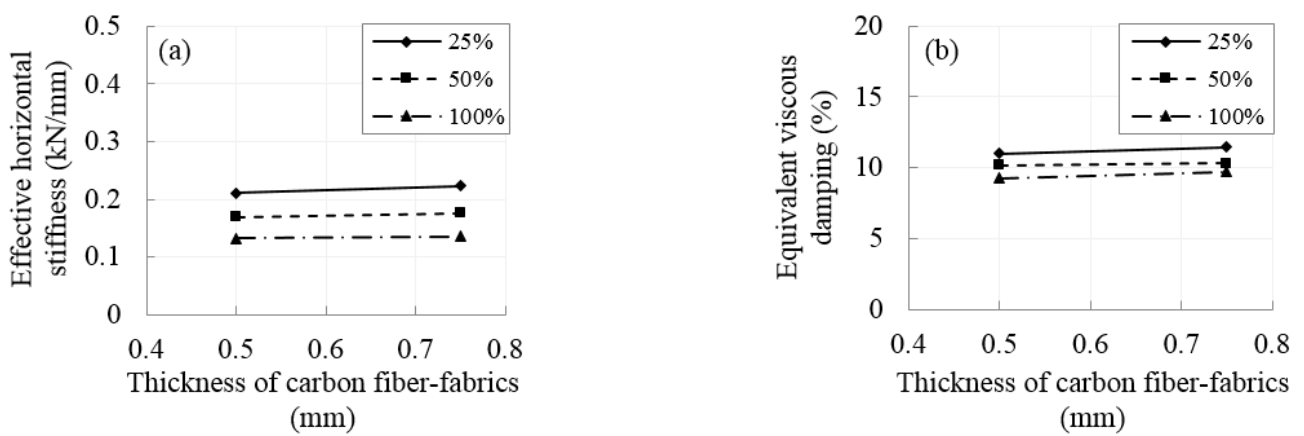

Figure 14. Effect of thickness of fiber-reinforced layers on (a) effective horizontal stiffness and (b) equivalent viscous damping of C-FREIs at $25 \%, 50 \%$, and $100 \%$ shear strains.

Slight changes were observed in the equivalent viscous damping when the thickness of reinforcement increased. This minor increase in the damping coefficient was due to using a higher amount of adhesive for three layers of fiber fabrics $\left(t_{f}=0.75 \mathrm{~mm}\right)$ compared to two layers $\left(t_{f}=0.50 \mathrm{~mm}\right)$ (Figure 14b). In the case of $t_{f}=0.75 \mathrm{~mm}$, three coats of adhesive are applied to three fiber fabric layers (one coat for each layer). The combination of bi-directional carbon fiber fabric and the adhesive (matrix) provided a flexible reinforcement. As a result, fiber-reinforced layers can slightly contribute to the energy dissipation and be considered as a minor source of energy damping.

In order to accurately investigate the condition of C-FREIs after conducting shear and compression tests, the elastomeric pad of C-FREI-B1 was detached from the supporting plates and then cut as shown in Figure 15. The laminated pad was checked for any internal delamination between rubber and fiber-reinforced layers. The specimen was cut using the water-jet in order to minimize or even eliminate any damage (e.g., debonding) that might occur during the cutting phase. As indicated in Figure 15, an internal delamination was observed between the exterior rubber layer and the first reinforcement at the top. The reason is that the interfacial stress in the layers, close to the top and bottom of the pad, exceeded the bonding strength of the adhesive and detachment occurs. Moreover, no delamination between internal layers shows the acceptable performance of the fiber-reinforced pads under shear and compression. 

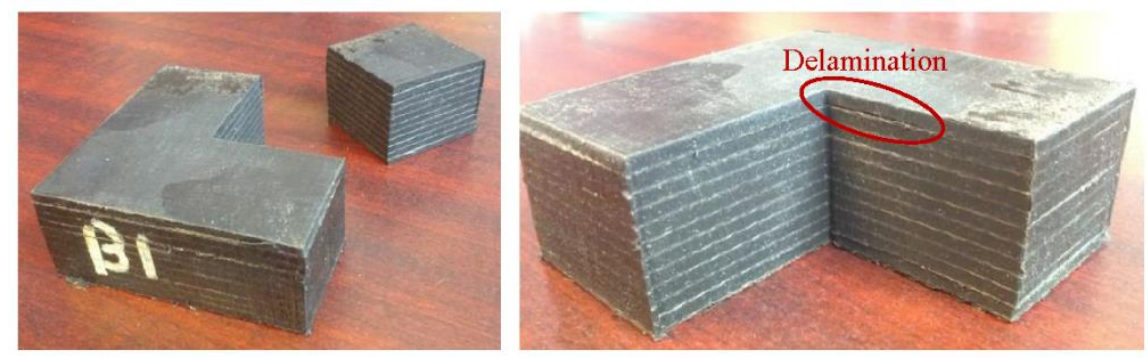

Figure 15. Detached carbon fiber-reinforced elastomeric pad (B1) after conducting shear and compression tests.

In order to check whether the manufactured C-FREIs possess advantages over steel-reinforced elastomeric isolators (SREIs), their performance (e.g., stiffness and damping ratio) were compared. Since the SREI was not fabricated through this study, the comparison was made between the manufactured C-FREIs and a SREI manufactured by Dehghani et al. [9]. It should be noted that the loading conditions (e.g., vertical pressure and shear strain magnitude) were the same for both cases. Based on the experimental results in this study, at $3 \mathrm{MPa}$ vertical pressure and $100 \%$ shear strain magnitude, the equivalent viscous damping of the manufactured C-FREIs ranged between $8.9 \%$ and $13.2 \%$, and the effective lateral stiffness varied from $0.094 \mathrm{kN} / \mathrm{mm}$ to $0.240 \mathrm{kN} / \mathrm{mm}$. Under $3 \mathrm{MPa}$ vertical pressure, the maximum vertical stiffness of C-FREIs was $147 \mathrm{kN} / \mathrm{mm}$ [18]. For the SREI, the equivalent viscous damping, and the effective horizontal and vertical stiffnesses were $8.0 \%$, $0.381 \mathrm{kN} / \mathrm{mm}$, and $153 \mathrm{kN} / \mathrm{mm}$, respectively. Results show that the C-FREIs have higher damping ratio and lateral flexibility, and a vertical stiffness that is comparable to that of the SREI. In terms of weight, the laminated pad of a SREI was 2.6 times heavier than that of a C-FREI.

\section{Conclusions}

Six $1 / 4$ scale carbon fiber-reinforced elastomeric isolators (C-FREIs) were manufactured and tested under different loading conditions including the vertical pressure and the cyclic lateral displacements. All C-FREIs consisted of laminated pads with identical lengths and widths (70 $\mathrm{mm}$ by $70 \mathrm{~mm}$ ) but different numbers and thicknesses of rubber and fiber-reinforced layers. The specimens were made of commercial high-quality neoprene layers that were bonded to bi-directional carbon fiber fabrics using an adhesive (rubber cement). The concluding remarks are summarized as follows.

- In order to make the manufacturing process fast and easy, long rectangular laminated pads were subjected to a uniform pressure of $4 \mathrm{MPa}$ for $24 \mathrm{~h}$ at the room temperature (around $23^{\circ} \mathrm{C}$ ) without using a mold. Then, they were cut to the required size.

- The equivalent viscous damping, which is a ratio of the dissipated energy to the restored elastic energy, increased from $9.1 \%$ to $13.2 \%$ when the total thickness of rubber increased from $12 \mathrm{~mm}$ to $24 \mathrm{~mm}$. This range of damping ratio shows that the commercial high-quality neoprene has a higher effective damping capability compared to the low-damping natural rubber.

- Increasing the vertical pressure from $1 \mathrm{MPa}$ to $3 \mathrm{MPa}$ showed that, within this range, the manufactured C-FREIs are almost insensitive to the compressive pressure regardless of the level of shear strain (25\% to $100 \%)$.

- For all C-FREIs, increasing the rate of the lateral displacement increased the effective horizontal stiffness. The maximum amount of increase was $10.4 \%$ when the rate changed from $20 \mathrm{~mm} / \mathrm{s}$ to $75 \mathrm{~mm} / \mathrm{s}$. By increasing the rate of the lateral cyclic loading, the elastomeric layers were stiffened, and, as a result, the rubber bearings showed a lower flexibility in the horizontal direction.

- Increasing the lateral cyclic rate from $20 \mathrm{~mm} / \mathrm{s}$ to $75 \mathrm{~mm} / \mathrm{s}$ reduced the equivalent viscous damping (from $14.1 \%$ to $12.2 \%$ ). The reason is that the stiffness of the rubber layers increases at high lateral cyclic rates. Consequently, the elastomeric isolator restores more energy, and the 
capability of the device in dissipating the earthquakes' energy degrades. Another point is that, compared to the high damping rubber, which has a highly nonlinear behavior, the neoprene used in the C-FREIs has a low sensitivity to the rate of the cyclic lateral displacements.

- At 100\% shear-strain amplitude, when the number of rubber layers was doubled (from 8 to 16), the effective horizontal stiffness decreased by $60 \%$ and the equivalent viscous damping increased by $22 \%$. At the same shear-strain level, increasing the thickness of fiber-reinforced layers from $0.5 \mathrm{~mm}$ to $0.75 \mathrm{~mm}$ slightly increased the lateral stiffness. This is because the fiber-reinforced layers become stiffer when their thickness increases. However, compared to the rubber layers, the effect of the reinforcement on the lateral flexibility was negligible. Some level of flexibility remains in the reinforcement after curing the bi-directional carbon fiber fabric impregnated by the adhesive. As a result, fiber-reinforced layers can slightly contribute to the energy dissipation and be considered as a minor source of energy damping.

\section{Future Recommendations}

By considering the limitations in this study, a few points should be noted. The maximum vertical pressure was limited to $3 \mathrm{MPa}$ because the C-FREIs were not designed for higher levels of pressure. It should be noted that, for low-rise residential buildings, the elastomeric bearings are subjected to a vertical pressure of around $3 \mathrm{MPa}$ [7]. However, in the bridge applications, the maximum allowable pressure reaches $10 \mathrm{MPa}$. In order to thoroughly assess the effect of the vertical load and also the lateral driving velocity on the response of C-FREIs, real-size rubber bearings should be designed, manufactured and tested in a future study.

In order to predict the response of the C-FREI, mathematical models can be established with certain key parameters. Experimental data can be used to calibrate the parameters of the model. By considering a specific number of factors (key parameters) and a minimum number of two levels for each factor, the total number of runs (specimens and experiments) increased beyond what we considered in this study. Therefore, more specimens need to be fabricated and further experimental and numerical investigations should be conducted in order to develop such mathematical models.

Since the effect of thickness of adhesive on the response of C-FREIs was not covered in this experimental study, this factor can be considered in future works. Furthermore, determining the curing level of adhesive using a differential scanning calorimeter (DSC) test can be also done in a future study. The reinforcement (carbon fiber-reinforced layers (CFR)) provides a vertical stiffness several hundred times the horizontal stiffness [18] and, as a result, the manufactured C-FREIs appear to be stable within the considered range of vertical pressure. However, a mechanical instability, known as the buckling phenomenon, can occur due to a low lateral stiffness [23]. In fact, when the horizontal stiffness is small, the rubber bearing can easily undergo a large lateral deflection. As a result, the effective plan area (i.e., an area which is effective in carrying the vertical load) noticeably reduces and the possibility of instability (buckling) increases. This instability can be recognized when the shear force encounters a significant reduction by increasing the shear strain. Another important point is that, although using thinner reinforcement layers reduces the weight of rubber bearings as an advantage, it can have an undesirable effect on the buckling load. The reason is that, by decreasing the thickness of reinforcement, both vertical and horizontal stiffnesses decrease. Therefore, while analyzing the buckling of elastomeric isolators, the effect of reinforcement's flexibility and thickness should be taken into account in addition to the shear deformation and warping of the cross section [24]. By replacing rigid steel shims with carbon fiber-reinforced layers, the thickness and flexibility of reinforcement change. In this situation, the stability of elastomeric isolators might be noticeably affected. Hence, further investigation is required to understand the buckling behavior of C-FREIs.

Acknowledgments: The financial contribution of the Natural Sciences and Engineering Research Council (NSERC) of Canada through the Engage grant program was critical to conduct this research and is gratefully acknowledged. The authors are grateful to Goodco Z-Tech Company, Laval, QC for providing bearing data and its support in the 
manufacturing stage. All the supports provided by Niel Van Engelen from the Department of Civil Engineering, McMaster University during testing at their facility are gratefully acknowledged.

Author Contributions: This work was a part of the PhD thesis by Farshad Hedayati Dezfuli under the direct supervision of M. Shahria Alam.

Conflicts of Interest: The authors declare no conflict of interest.

\section{References}

1. Ozbulut, O.E.; Mir, C.; Moroni, M.O.; Sarrazin, M.; Roschke, P.N. A fuzzy model of superelastic shape memory alloys for vibration control in civil engineering applications. Smart Mater. Struct. 2007, 16, 818-829. [CrossRef]

2. Kunde, M.C.; Jangid, R.S. Seismic behavior of isolated bridges: A-state-of-the-art review. Electron. J. Struct. Eng. 2003, 3, 140-170.

3. Kelly, J.M. Analysis of fiber-reinforced elastomeric isolator. Jpn. Soc. Eng. Educ. 1999, 2, 19-34.

4. Kelly, J.M. Seismic isolation systems for developing countries. Earthq. Spectra 2002, 18, 385-406. [CrossRef]

5. Moon, B.Y.; Kang, G.J.; Kang, B.S.; Kelly, J.M. Design and manufacturing of fiber reinforced elastomeric isolator for seismic isolation. J. Mater. Process. Tech. 2002, 130-131, 145-150. [CrossRef]

6. Toopchi-Nezhad, H.; Tait, M.J.; Drysdale, R.G. Lateral response evaluation of fiber-reinforced neoprene seismic isolators utilized in an unbonded application. J. Struct. Eng. 2008, 134, 1627-1637. [CrossRef]

7. Toopchi-Nezhad, H.; Tait, M.J.; Drysdale, R.G. Testing and modeling of square carbon fiber-reinforced elastomeric seismic isolators. Struct. Control Health Monit. 2008, 15, 876-900. [CrossRef]

8. Tsai, H.C.; Kelly, J.M. Stiffness analysis of fiber-reinforced rectangular seismic isolators. J. Eng. Mech. 2002, 128, 462-470. [CrossRef]

9. Dehghani Ashkezaria, G.; Aghakouchaka, A.A.; Kokabib, M. Design, manufacturing and evaluation of the performance of steel like fiber reinforced elastomeric seismic isolators. J. Mater. Process. Tech. 2008, 197, 140-150. [CrossRef]

10. Mordini, A.; Strauss, A. An innovative earthquake isolation system using fiber reinforced rubber bearings. Eng. Struct. 2008, 30, 2739-2751. [CrossRef]

11. Zhang, H.; Peng, T.; Li, J.; Li, W. Experimental study of FRP rubber bearing. Adv. Mater. Res. 2011, 169-170, 1621-1624. [CrossRef]

12. Pauletta, M.; Cortesia, A.; Russo, G. Roll-out instability of small size fiber-reinforced elastomeric isolators in unbonded applications. Eng. Struct. 2015, 102, 358-368. [CrossRef]

13. Van Engelen, N.C.; Osgooei, P.M.; Tait, M.J.; Konstantinidis, D. Experimental and finite element study on the compression properties of Modified Rectangular Fiber-Reinforced Elastomeric Isolators (MR-FREIs). Eng. Struct. 2014, 74, 52-64. [CrossRef]

14. Osgooei, P.M.; van Engelen, N.C.; Konstantinidis, D.; Tait, M.J. Experimental and finite element study on the lateral response of modified rectangular fiber-reinforced elastomeric isolators (MR-FREIs). Eng. Struct. 2015, 85, 293-303. [CrossRef]

15. Russo, G.; Pauletta, M.; Cortesia, A. A study on experimental shear behavior of fiber-reinforced elastomeric isolators with various fiber layouts, elastomers and aging conditions. Eng. Struct. 2013, 52, 422-433. [CrossRef]

16. Al-Anany, Y.M.; Tait, M.J. A numerical study on the compressive and rotational behavior of fiber reinforced elastomeric isolators (FREI). Compos. Struct. 2015, 133, 1249-1266. [CrossRef]

17. Hedayati Dezfuli, F.; Alam, M.S. Multi-criteria optimization and seismic performance assessment of carbon FRP-based elastomeric isolator. Eng. Struct. 2013, 49, 525-540. [CrossRef]

18. Hedayati Dezfuli, F.; Alam, M.S. Performance of carbon fiber-reinforced elastomeric isolators manufactured in a simplified process: Experimental investigations. Struct. Control Health Monit. 2014, 21. [CrossRef]

19. Canadian Standard Association (CSA). Canadian Highway Bridge Design Code (CHBDC); CAN/CSA-S6-06; CSA: Rexdale, ON, Canada, 2006.

20. ACP Composites Inc. Product Specification Sheet; ACP Composites Inc.: Livermore, CA, USA, 2012.

21. Kang, B.S.; Kang, G.J.; Moon, B.Y. Hole and lead plug effect on fiber reinforced elastomeric isolator for seismic isolation. J. Mater. Process. Tech. 2003, 140, 592-597. [CrossRef]

22. Kelly, J.M. Earthquake-Resistant Design with Rubber, 2nd ed.; Springer: London, UK, 1997. 
23. Naeim, F.; Kelly, J.M. Design of Seismic Isolated Structures: from Theory to Practice; John Wiley \& Sons: New York, NY, USA, 1999.

24. Tsai, H.S.; Kelly, J.M. Buckling load of seismic isolators affected by flexibility of reinforcement. Int. J. Solids Struct. 2004, 42, 255-269. [CrossRef] 